\title{
Social life cycle assessment of an innovative industrial wastewater treatment plant
}

\author{
Monica Serreli ${ }^{1} \cdot$ Luigia Petti $^{1}$ [ $\cdot$ Andrea Raggi ${ }^{1} \cdot$ Alberto Simboli $^{1} \cdot$ Guglielmo luliano ${ }^{2}$
}

Received: 24 February 2021 / Accepted: 12 June 2021 / Published online: 6 August 2021

(c) The Author(s) 2021

\begin{abstract}
Background The social impacts generated by industrial waste treatment processes have not been studied enough, as shown in the literature. Social life cycle assessment studies have mainly focused on the assessment of products and less on industrial waste, especially wastewater, although potentially relevant from an environmental point of view, and also from a social one for various stakeholders.

Purpose This case study concerns the social assessment of an innovative technology to treat the wastewater of a microelectronics company. In order to produce electronic components and semiconductors, the company has to treat and dispose of relevant wastewater streams containing various toxic substances. The wastewater streams need to be treated in order to protect the eco-system, representing a high cost for the company and a potential impact on the environment.

For this reason, the company developed a LIFE project to demonstrate the viability to decrease the burdens on water bodies. The positive outcome of the test on the pilot plant paved the way for the construction of the full-scale plant that will treat all the wastewater generated by the company.

The objective of this paper is the socio-economic assessment of a full-scale plant designed to treat three different kinds of wastewater.

Methods The assessment of socio-economic potential impacts of a new technology has been carried out through the PSILCA (Product Social Impact Life Cycle Assessment) database implementation to evaluate 65 social indicators of a wastewater treatment plant.

Results The line with the highest impact is the one which treats tetramethylammonium hydroxide; this is because this wastewater flow is the most abundant (14 and 43 times greater than the other wastewaters, respectively).

The most affected stakeholder is the Local Community, followed by the Actors of the Value Chain; in fact, the results referred to the functional unit considered exceed 300,000 medium risk hours in both cases. For the Local Community this result arises from the indicator "Contribution to environmental load," which is understandable considering the object of the study since this indicator includes health effects. As far as the Value Chain Actors stakeholder is concerned, the two indicators most impacted are "Corruption" and "Social responsibility along the supply chain".

The analysis conducted has also shown that upstream has a fundamental relevance for the social risks detected.

Conclusions Considering the current lack of studies on both environmental and social impacts of wastewater treatment, and the fact that Social Life Cycle Assessment has not been widely used in this field, as emerged from literature review, this work is the first use of the PSILCA database to assess an industrial wastewater plant. The use of a social life cycle assessment database allows the value chain of a product system to be considered: the results show that most of the overall social risk derives from upstream sectors.
\end{abstract}

Keywords S-LCA · Social life cycle assessment - Wastewater treatment (WWT) · PSILCA · Electronics and semiconductor (E\&S) sector · Tetramethylammonium hydroxide (TMAH)

Communicated by Marzia Traverso

Luigia Petti

1.petti@unich.it

Extended author information available on the last page of the article

\section{Nomenclature}

AHP Analytic hierarchy process

ANP Analytic network process

BES Bio-electrochemical systems

DoS Dashboard of sustainability 


\begin{tabular}{|c|c|}
\hline$E \& S$ & Electronics and semiconductor \\
\hline GDP & Gross domestic product \\
\hline MRIO & Multi-regional input output \\
\hline $\mathrm{mrh}$ & Medium risk hours \\
\hline PSILCA & Product Social Impact Life Cycle Assessment \\
\hline REACH & $\begin{array}{l}\text { European Regulation on Registration, } \\
\text { Evaluation, Authorisation and Restriction of } \\
\text { Chemicals }\end{array}$ \\
\hline SAM & Subcategory assessment method \\
\hline SHDB & Social hotspot database \\
\hline TMAH & Tetramethylammonium hydroxide \\
\hline USD & US dollar \\
\hline WWT & Wastewater treatment \\
\hline WWTF & Wastewater treatment facilities \\
\hline WWTP & Wastewater treatment plant \\
\hline
\end{tabular}

\section{Introduction}

Chemicals have become essential to several production and consumption processes; however, some of them can severely damage human health or the environment. In the second half of the last century, the global production of chemicals grew over 50-fold leading to a huge amount of newly registered global chemicals (EC 2019), thus mounting the chemical burden worldwide. In recent years, the EU has undertaken numerous actions to regulate and improve the production, use and disposal of toxic substances, as given in REACH (European Regulation on Registration, Evaluation, Authorisation and Restriction of Chemicals-EC 2006)—aiming at ameliorating human health and environment safeguard by means of identifying the inherent properties of chemicals—or the 7th Environment Action Programme (EC 2013) adopted to come up with an innovative strategy for a safe environment. These actions were characterized by a proactive approach, which helped to enhance innovation and competitiveness in the EU chemical sector.

Despite this, great advances can still be made to improve the sustainability of chemicals, which are widely used both in various industrial sectors, among which are the electronics and semiconductor (E\&S) sector.

The use of highly pure chemicals is of great importance in the semiconductor industry; in fact, minor traces of impurities can critically affect the electrical properties of materials. In the production of printed circuit boards, the photosensitive resin applied to the substrate (wafer) is exposed to light using a mask on defined points and then developed in a chemical reaction. The developer contains a certain concentration of tetramethylammonium hydroxide (TMAH) and ensures that the areas exposed to light can be easily removed from the substrate. TMAH $\left(\mathrm{N}\left(\mathrm{CH}_{3}\right)_{4}{ }^{+} \mathrm{OH}^{-}\right.$; CAS 75-59-2) is an alkaline ingredient (a colourless to light yellow solution that is miscible with water and has similar density) in photoresist developer, in concentrations of $2.38-2.62 \%$ (by weight) in a great number of applications.

Given that large amounts of developer are used in E\&S industries, a considerable amount of wastewater containing TMAH is generated every year by this sector. Based on empirical investigations carried out and taking into account the size of the European E\&S sector, it can be estimated that more than 250,000 $t$ of TMAH solution are used every year in Europe (more than 2 million tons/year worldwide) (Life Bitmaps 2020).

As concerns the ecotoxicity on the water environment, the OECD (2012) reported that TMAH degrades quickly in water and has a scarce bio-accumulation capacity. Nevertheless, fatal accidents were described due to the high toxicity of TMAH, which is lethal in both concentrated and diluted formulations (at 2.38\% by weight) (Lin et al. 2010; Lee et al. 2016; Mori et al. 2015).

In spite of that, it must be noted that TMAH emission levels are currently not regulated, e.g. by any EU or Italian regulation (EC 2006).

Technical notes reveal that the NOEC (no observed effect concentration)-acceptability concentration of TMAH to prevent chronic toxic effects on invertebrates (Ceriodaphnia dubia, Daphnia magna)—should be equal to $0.02 \mathrm{mg} / \mathrm{L}$ (OECD 2012). Considering a safety factor of 10, as foreseen by the EU Water Framework Directive 2000/60/EC, the Italian Istituto Superiore di Sanità (ISS, Higher Institute of Health) came out with a recommendation to keep the discharge limits below $0.4 \mathrm{mg} / \mathrm{L}$ in the drainage system to ensure $0.2 \mathrm{mg} / \mathrm{L}$ thresholds in water bodies (ISS 2013).

Hence, a tremendous volume of wastewater carrying TMAH is released every day from the E\&S industry and the current operational limit can be considered adequate for human safety but not for protecting the water ecosystem (Vegliò 2016). Additionally, the cost for the disposal or the chemical treatment of spent TMAH solution significantly affects the operational costs in the E\&S industry. Thus, technically viable and economically sustainable solutions would be very welcome and advanced treatments of industrial wastewaters, spent TMAH and photoresist process solutions represent a key challenge for the $\mathrm{E} \& \mathrm{~S}$ industry.

The purpose of this paper is to evaluate the socio-economic aspects of implementing the above wastewater treatment technologies at a full-scale by means of a social life cycle assessment (S-LCA).

The outline of this paper is as follows: the next section illustrates the background of the scientific literature concerning the social assessment of wastewater treatment technologies. The specific objectives of the study, the methodology used and the boundaries of the system analysed are 
described in Sec. 3. The data collected are shown in Sec. 3.4, while the impacts detected and the results obtained are discussed in Sec. 4. Some conclusions are finally drawn in Sec. 5 .

\section{Literature background}

In order to conduct a socio-economic analysis, it is useful to look over what the literature proposes in this field.

In the analysis of the literature background, S-LCA studies on industrial wastewater treatment (WWT) or, more generally, on WWTs, were considered by focusing on which social aspects of WWTs were assessed in the S-LCA case studies and on the methodology used. Also, the specific indicators utilised to assess the social aspects of a WWT in S-LCA studies were taken into consideration.

Any study on WWT that included the assessment of social aspects published in scientific journals between 2009 and 2020 has been taken into account. Instead, the following was not considered: grey literature, duplicate studies, conference papers and papers by the same authors on the same subject and works not written in English.

The timeframe (2009-2020) for the literature search was chosen to start from 2009, because it was when the S-LCA guidelines (UNEP/SETAC 2009) were first published; therefore, earlier studies, if any, are supposed to have not been carried out in compliance with the most widely recognised relevant guidelines. For this purpose, Scopus was consulted. The search topics were included in the Title-Abstract-Keyword field. The most relevant results are those obtained from the following keywords: "Social life cycle assessment" AND "wastewater treatment"; "social assessment" AND "wastewater treatment".

The papers identified were reviewed for the methodology applied and the stakeholders and the social indicators involved for each of the case studies (Table 1).

The low number of works found suggests that, despite that considerable progress has been made on WWT technologies, only few studies have evaluated the social consequences of the WWT processes.

García-Sánchez and Güereca (2019) conducted an S-LCA on the WWT of Mexico City and considered only the workers' stakeholder. They obtained the highest social performance average in the phase of the WWT, whilst the storage phase obtained the poorest rating. They concluded that water systems need an S-LCA methodology with specific indicators to help the decision-making process.

Padilla-Rivera et al. (2019) proposed a useful metric to decide which is the best WWT from an environmental, social and economic perspective. In selecting the appropriate indicators, they considered that, up to now, the emphasis on wastewater has been on the epidemiological features and their consequences on health and on the social aspects of its use, mainly linked to irrigation. Another concern has been how wastewater practices have been dealt with by institutions. Therefore, they decided to consider the following stakeholders and indicators:

- Community and society: public participation, local employment, safe and healthy living conditions

- Workers: working hours, fair salary, training, health and safety

- Consumers: feedback mechanism

- Supply chain: promoting social responsibility (PadillaRivera et al. 2019, p. 23)

Sadhukhan et al. (2019), in their case study carried out by means of the Social Hotspots Database (SHDB), recommended the practice of macroalgae growing as a more sustainable option for wastewater treatment. Shemfe et al. (2018) used the same database in the analysis of the sustainability of bio-electrochemical systems (BES), which was classified as a technical solution for a few urgent worldwide problems, such as environmental pollution, scarcity of resources and scarcity of freshwater. Finally, this study assessed positively the results obtained from the analysis carried out on BES with the SHDB.

Amaral et al. (2019) evaluated the treatment and disposal of biological sludge and biogas in a wastewater Brazilian plant (WWTP) by means of Dashboard of Sustainability (DoS) (Traverso et al. 2012) which makes for the conversion of data into a sole sustainability indicator and the weighting of every indicator for the same scale.

Kamali et al. (2019) assessed the sustainability of the treatment of industrial effluents by means of engineered nanomaterials. In this case, the social indicators used are odour, noise, visual impacts and public acceptance.

In the paper by Opher et al. (2018), the benefits and social impacts of four alternative re-use of non-potable domestic urban water are compared: (1) central WWT, no urban reuse, the recovered water is discharged into nature; (2) central WWT and urban re-use of the tertiary effluent of the WWTP; (3) semi-distributed grey water treatment and its re-use; and (4) distributed grey water treatment and its re-use within each apartment building.

The selected subcategories and indicators useful for evaluating them are listed below.

- Public: water saving/equity

- Local community: community engagement/local employment/urban landscape

- Consumers' health: concerns (level of contact with the reclaimed water, source of the reclaimed water, trust in supplier), household expenses, convenience 


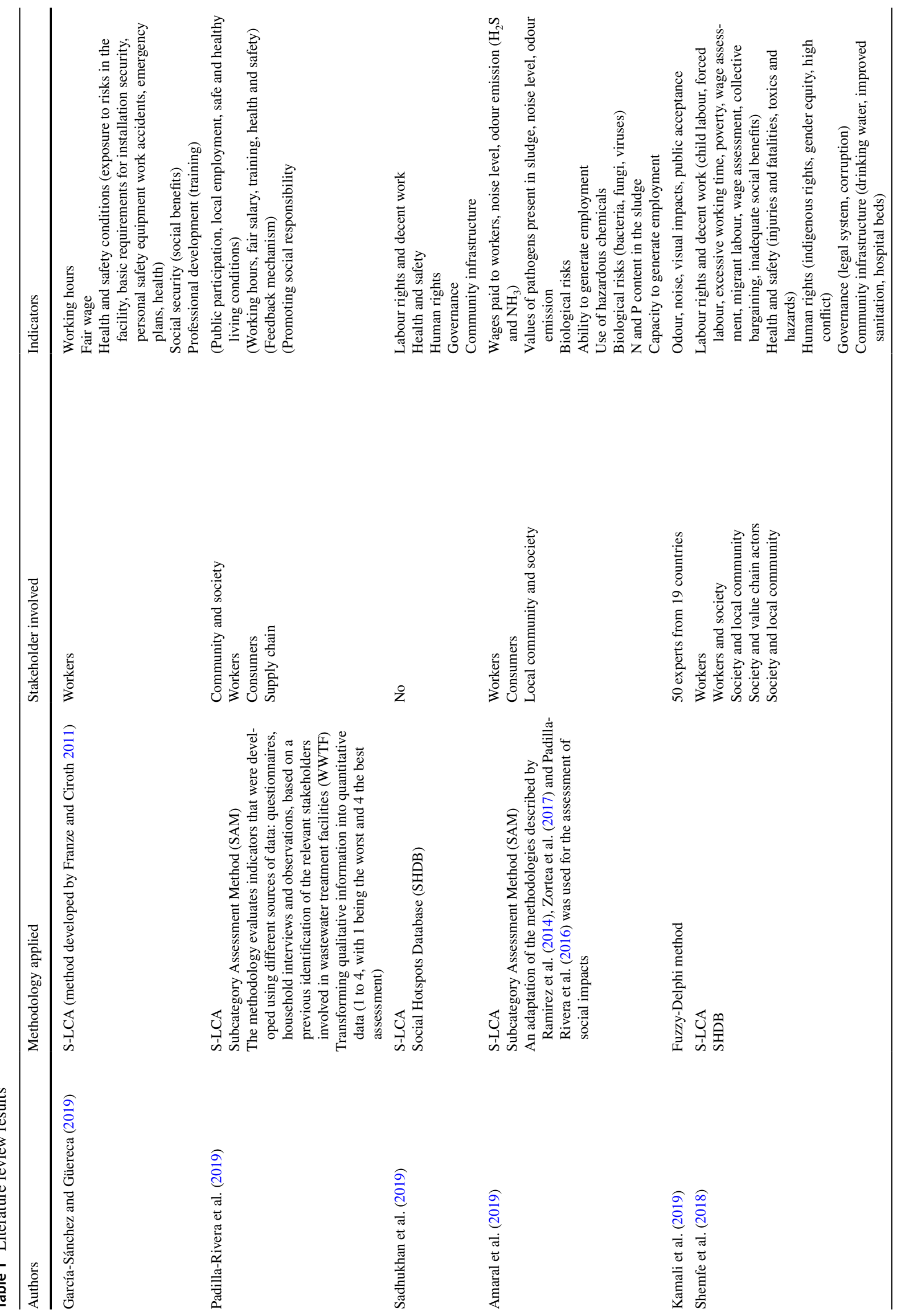




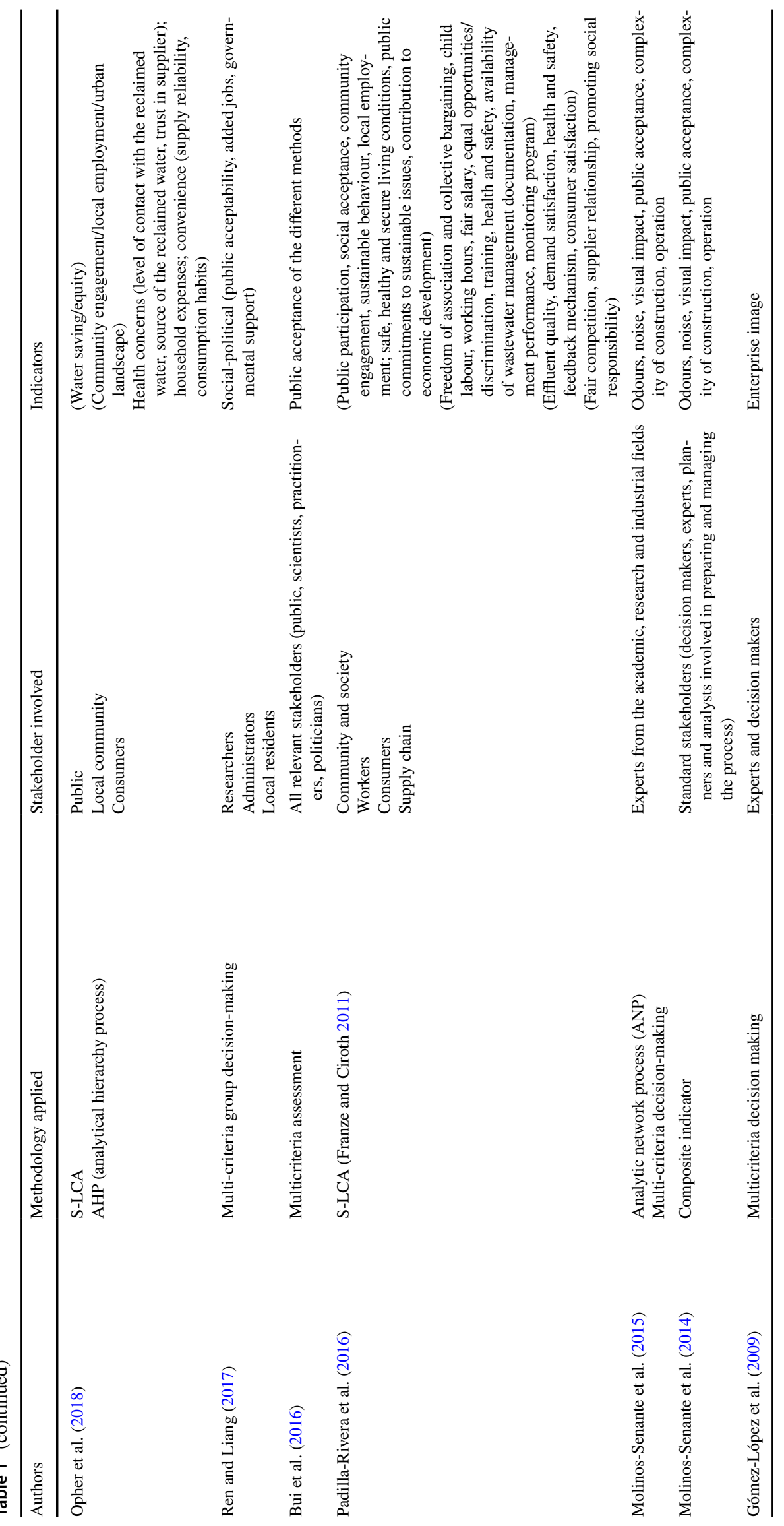


As for the case study, the re-use of distributed urban water resources had a positive impact, due to the promotion of public commitment for natural water resources conservation and the promotion of community commitment.

Ren and Liang (2017) proposed a method to help decision-makers in choosing the most sustainable WWT among different processes; the social criteria used are related to the public acceptability of the plants, to the jobs created by the plants and to the policy supports, i.e. fiscal and policy/ regulation enhancement.

Byrne et al. (2017) reviewed the S-LCA studies on urban water infrastructure. Despite, they collected 22 studies on various urban water systems worldwide, only two of them (Kobayashi et al. 2015; Sharma et al. 2009) had assessed the social themes, by using neither S-LCA nor the stakeholder Workers. The other 20 case studies had focused solely on the assessment of environmental impacts and, in three cases, of the economic ones.

Bui et al. (2016) used multi-criterion analysis to assess micropollutants treatments by means of full-scale and pilotscale studies; the social indicator used was public acceptance of different treatment methods.

Padilla-Rivera et al. (2016) measured social performance by using a 25-indicator framework to assess and compare two different WWTs in Mexico at both urban and rural locations.

Molinos-Senante et al. $(2014 ; 2015)$ proposed to use an analytic network process or to elaborate a composite indicator useful to favour the evaluation of various types of WWT. In reference to this, they considered the following indicators: odours, noise, visual impact, public.
Gómez-López et al. (2009) aimed at choosing the best methods of disinfection of treated wastewater prior to its re-use, as well as considering enterprise image as a social indicator.

Lessons learned from the analysis of the 14 papers using S-LCA or having assessed social aspects in WWT are the following:

- The analysis of the literature has not shown any element useful to draw methodological conclusions, the S-LCA studies are very few and no industrial WWT assessment has been found among these.

- Technical and financial aspects have the precedence in wastewater treatment facilities (WWTF), whereas social aspects have not been completely assessed. Therefore, no method for their evaluation has been yet acknowledged.

- At present, most of the research focuses on finding the most economically and environmentally sustainable method for wastewater treatment. Furthermore, the social aspects have been considered almost exclusively in studies dealing with the treatment of wastewater from civil plants, although it is evident that the greatest problems for humans arise from wastewater coming from industries and agriculture (UN Water 2020).

- Most of the analysed studies are very recent (from 2015 to 2019). From 2009 to 2015 , only two case studies were found. In this period, the analysis of the sustainability of WWT systems mainly considered environmental and economic aspects and the social features concerned only the public acceptance of the external physical aspects of WWT.

Fig. 1 Current WWT

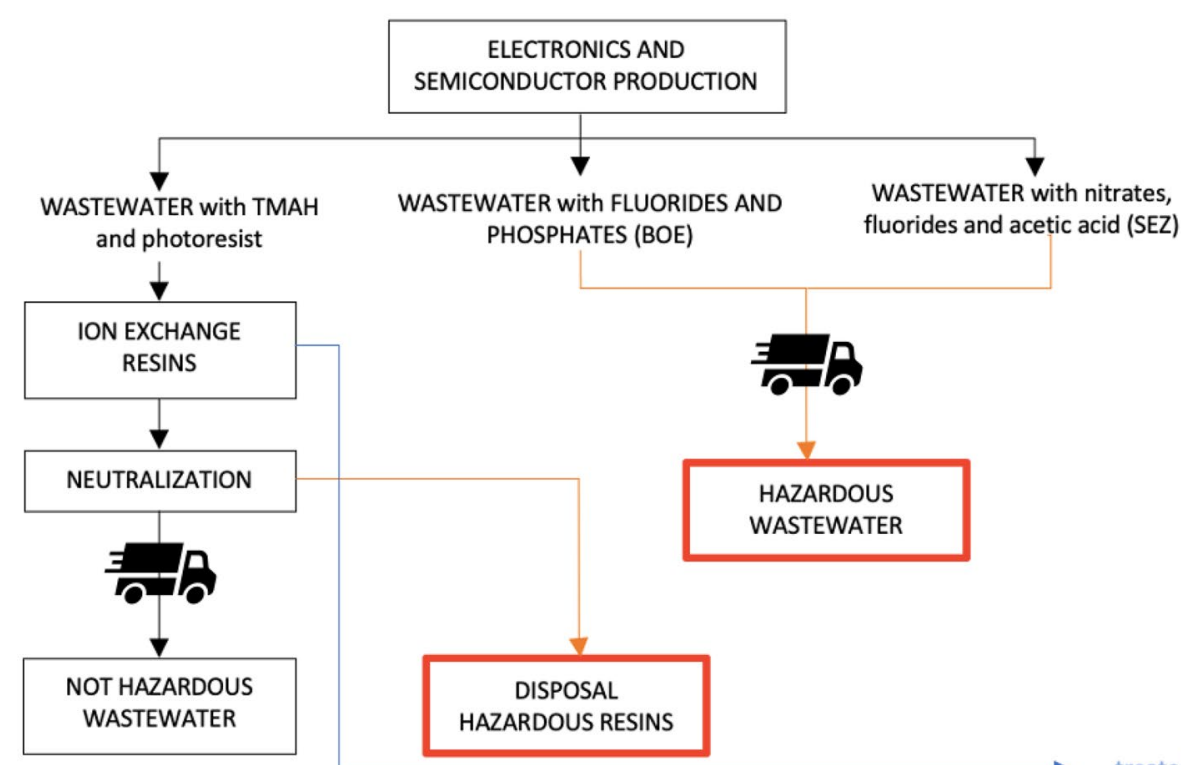




\section{Methods}

Approaches for the evaluation of social impacts are still under development. S-LCA is a method proposed to measure the social and socio-economic impacts of products and/or processes from cradle to grave (i.e. from raw material extraction to their end of life) (UNEP/ SETAC 2009).

The case study carried out regards an E\&S company situated in the Abruzzo region, Italy. Prior to the project, the company neutralized the TMAH used in semiconductor manufacturing using $\mathrm{H}_{2} \mathrm{SO}_{4}$ and $\mathrm{NaOH}$. By so doing, the TMAH was concentrated, resulting in a lower volume. This solution was then kept and sent to an external plant authorized to treat such waste (Fig. 1). The WW from the other two lines, line 2 (named BOE) and line 3 (named SEZ), was not treated on site, but sent to external companies for disposal. The Regional Agency for the Environment Protection of Abruzzo region, based on the ISS technical note (ISS 2013), issued to the company under study a recommendation to investigate viable solutions for reducing the TMAH concentration in its plant (Regional Agency for the Environment Protection of Abruzzo Region 2013).

The company decided to build a pilot plant to test a new treatment technology for the three WW lines internally, instead of disposing of WW externally, thus hoping to gain significant savings in the operating costs related to waste treatment and to improve the environmental impacts generated by these three lines.
This article deals with an experimental project on the biodegradation of TMAH (line 1) in a proper bioreactor (De Michelis et al. 2019). The aim of the project was to implement a TMAH biological treatment plant on a pilot scale, which went into operation in 2018. Subsequently, the project demonstrated that the biodegradation of TMAH into non-toxic substances and ammonia can take place on an industrial scale using aerobic biological treatment, with an efficiency greater than 99\% (Innocenzi et al. 2019). The new technology plant provided treatment of line 1 by neutralisation with sulphuric acid, followed by biological treatment (De Michelis et al. 2019) (Fig. 2).

The second WW lines carried fluorides and phosphates (BOE-line 2), while the third was abundant in nitrates, fluorides, phosphoric acid and acetic acid (SEZ-line 3). These lines were chemically treated with lime together with aluminium sulphates $\left(\mathrm{Al}_{2}(\mathrm{SO})_{4} * 18 \mathrm{H}_{2} \mathrm{O}\right)$ added as a coagulant. Lime allowed the solutions to be neutralized by precipitating the impurities: indeed, lime was able to successfully eliminate pollutants from residual solutions. Thereafter, filtration enabled the separation of solid and liquid phases.

The liquid streams, produced at the end of the three lines, are treated in a biological reactor, water, can then be recycled and/or discharged into surface waters (Innocenzi et al. 2019).

Regarding the solid waste produced by lines 2 and 3, the classification as non-hazardous was confirmed by the pilot plant tests (De Michelis et al. 2019).

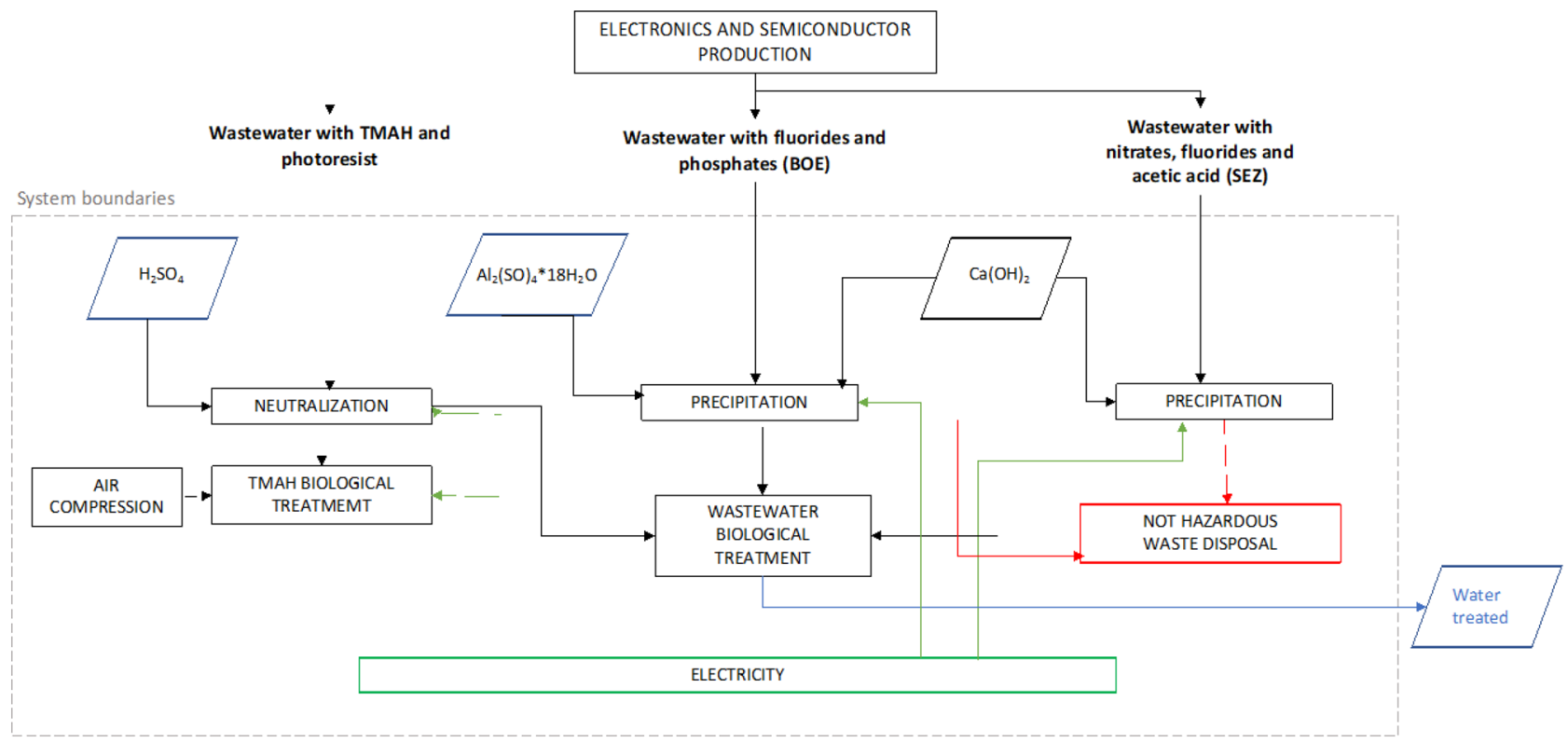

Fig. 2 System boundaries for LCA and S-LCA of the full-scale plant 
The pilot plant worked as a test for the future construction of a full-scale plant. The analysis carried out considered the volumes that the full-scale plant will have to handle, because the company was interested in assessing the social risks related to it.

\subsection{Goal of the study}

The aim of this study is to assess the socio-economic aspects of a new wastewater treatment technology used to control the pollution arising from the production of semiconductors carried out in the company's facilities located in Abruzzo, Italy. The current technology only partially treats WW streams, whilst the new technology, which was tested on a pilot plant, treats all three types of WW. The analysis considered the flows of a full-scale plant, which are planned to be built after a positive evaluation of the project.

\subsection{Tools}

This study was carried out using Product Social Impact Life Cycle Assessment-PSILCA v2.0 (Eisfeldt and Ciroth 2017), a comprehensive database developed by Green-Delta GmbH in Berlin, available within the open-source LCA software "openLCA" (www.openlca.org). PSILCA uses a multiregional input/output database called Eora (Eora 2015) to provide information for 189 countries and almost 15,000 different sectors, divided into industries and commodities. Like many input/output tables, Eora considers cash flows between processes. Input/output tables are an accounting representation of the exchange flows occurring in a given economic system, over a given period of time. The inputs of each sector are expressed in terms of USD needed to produce US $\$ 1$ of output.

Social indicators are structured according to the Guidelines for Social Life Cycle Assessment of Products (UNEP/ SETAC 2009).

PSILCA uses worker-hours as its activity variable to quantify the impacts of a process along its life cycle, although the addition of further variables is currently being analysed.

The PSILCA database proposes 65 qualitative and quantitative indicators, measured in various units, such as single values or percentages. They are structured in clusters describing 19 social and socio-economic subcategories related to UNEP/SETAC (2009). Indicator values defined as "intensive" and independent of the system size (e.g. size of the sector or economy density) are given in the PSILCA database, so as to render the indicator results comparable across countries and different sectors.

The indicators are quantified in medium risk hours (mrh), i.e. hours with an average risk of an occurring given social issue.
The subcategories focus on five stakeholder categories: workers, local community, society, consumers and value chain actors.

\subsection{Scope of the study}

\subsubsection{Functional unit}

The plant treats three different kinds of wastewater, with different treatments. The social assessment is consistent with the environmental life cycle assessment (LCA) conducted on the pilot plant, the full scale and the current management (Life Bitmaps 2020).

The functional unit used for the analysis is the same as that chosen for the LCA, i.e. the current annual generated amounts for each kind of wastewater considered, as specified below:

1. $6300 \mathrm{t}$ of wastewater with TMAH and photoresist (line $1)$;

2. $435 \mathrm{t}$ of wastewater with $\mathrm{NH}_{4} \mathrm{~F}$ (BOE) (line 2);

3. $145 \mathrm{t}$ of wastewater with nitrates, fluorides, phosphoric acid and acetic acid (SEZ) (line 3).

\subsubsection{System boundaries}

The system boundaries were also defined consistently with the environmental LCA study (Fig. 2).

In the current management option, the wastewater with TMAH and photoresist is treated internally (ion exchange and neutralisation) and then managed by external companies, while the other two types of wastewaters are not currently treated within Company facilities but are sent to external companies for treatment as hazardous wastewater.

As regards the plant with innovative processes, the system boundaries include, for line 1, sulphuric acid and biological treatments. While for the other two lines, precipitation and filtration were included. Finally, a treatment in a biological reactor for all the three lines is considered.

In principle, for a comparison between the full-scale system with new technology and the current system to be meaningful, the overall social impacts generated by both systems should be assessed. As regards that aim, in the current system, the processes carried out by the companies currently treating the waste disposal (for line $2 \mathrm{BOE}$ and line 3 SEZ) should also be included in the system boundaries. However, for consistency reasons, the system boundaries of this study are the same as those of the environmental LCA study and, therefore, as regards the current system, they include only transportation to the external companies that treat wastewater. 
Table 2 Input data, origin and Eora sector category for the three lines of wastewater treated within the full-scale innovative processes

\begin{tabular}{|c|c|c|c|}
\hline Material & Input (tons per year) & $\begin{array}{l}\text { Origi- } \\
\text { nating } \\
\text { from }\end{array}$ & Eora sector \\
\hline \multicolumn{4}{|c|}{ Wastewater with TMAH and photoresist } \\
\hline Wastewater & $6300 \mathrm{t}$ & Italy & Waste Flow \\
\hline Sulphuric acid (98\%) & $23.62 \mathrm{t}$ & Italy & Chemicals, chemical products and man-made fibres \\
\hline Water & $55.12 \mathrm{t}$ & Italy & Collection, purification and distribution of water \\
\hline Electricity & $630,000 \mathrm{kWh}$ & Italy & Electrical energy, gas, steam and hot water \\
\hline \multicolumn{4}{|c|}{ Wastewater with fluorides and phosphates $\mathrm{NH}_{4} \mathrm{~F}(\mathrm{BOE})$} \\
\hline Wastewater & $435 \mathrm{t}$ & Italy & Waste Flow \\
\hline Lime & $102.6 \mathrm{t}$ & Italy & Chemicals, chemical products and man-made fibres \\
\hline Water & $410.25 \mathrm{t}$ & Italy & Collection, purification and distribution of water \\
\hline $\mathrm{Al}_{2}\left(\mathrm{SO}_{4}\right)_{3} * 18 \mathrm{H}_{2} \mathrm{O}$ & $17.4 \mathrm{t}$ & Italy & Chemicals, chemical products and man-made fibres \\
\hline Electricity & $7500 \mathrm{kWh}$ & Italy & Electrical energy, gas, steam and hot water \\
\hline \multicolumn{4}{|c|}{ Wastewater with nitrates, fluorides and acetic acid (SEZ) } \\
\hline Wastewater & $145 \mathrm{t}$ & Italy & Waste Flow \\
\hline Lime & $33.95 \mathrm{t}$ & Italy & Chemicals, chemical products and man-made fibres \\
\hline Water & $135.7 \mathrm{t}$ & Italy & Collection, purification and distribution of water \\
\hline $\mathrm{Al}_{2}\left(\mathrm{SO}_{4}\right)_{3} * 18 \mathrm{H}_{2} \mathrm{O}$ & $5.8 \mathrm{t}$ & Italy & Chemicals, chemical products and man-made fibres \\
\hline Electricity & $2500 \mathrm{kWh}$ & Italy & Electrical energy, gas, steam and hot water \\
\hline
\end{tabular}

\subsubsection{Assumptions}

The material inputs shown in Table 2 were entered in PSILCA as economic value and were provided by the company.

The economic value of all the inputs has been converted from euro to USD using a deflator into USD 2011, as the current version of PSILCA is based on USD 2011 (\$1.2939 to the euro).

\subsection{Inventory analysis}

\subsubsection{Full-scale plant, data collection}

The data required by the PSILCA database to model the product systems are: input materials, their origin, the Eora MRIO database category, the total cost of each input material and the working hours needed for the 3 WWT.

The product systems modelled on PSILCA are the three wastewater lines of the new full-scale plant.

Table 2 summarizes the input data, their country of origin and the Eora sector category for the full-scale plant. All data and estimates were provided by the company. An average Italian power mix is chosen as energy source to feed all the main process blocks, the PSILCA database uses energy mix data from Istat (the Italian Statistical Office) referring to 2011 (Istat 2014).

\subsection{Impact assessment}

The risk level of indicators is assessed for the product system and entered in the output table. Indicators are then "characterized" by the activity variable. The characterisation factors used are expressed on an ordinal scale and divided into 6 levels as follows: no risk $=0$, very low risk $=0.01$, low risk $=0.1$, medium risk $=1$, high risk $=10$, very high risk $=100$ and a missing value (no data) equals to very low risk. The activity variable used by PSILCA is worker hours, i.e. the time spent by each worker to manufacture a certain quantity of product in a process/sector. "Worker hours" allow us to quantify the social risks to which each worker is affected in a product system.

To build the DB for each process the amount of worker hours has been computed in relation to US $\$ 1$ of output (Eisfeldt and Ciroth 2017).

Worked hours $=\frac{\text { unit labour cost }\left(\frac{U S D}{U S D}\right)}{\text { mean hourly labour } \operatorname{cost}\left(\frac{U S D}{h}\right)}$

The unit labour cost is the compensation of employees for US $\$ 1$ output within a sector, and it is expressed in USD. The mean hourly labour cost is the average hourly wages, and it is expressed in USD for $1 \mathrm{~h}$. The equation result is expressed in hours of work per 1 USD of output. 
Table 3 Stakeholders, subcategories and indicators in the PSILCA database

\begin{tabular}{|c|c|c|c|}
\hline Stakeholder & Subcategory & Indicator & Risk level \\
\hline \multirow[t]{24}{*}{ Workers } & \multirow[t]{3}{*}{ Child labour } & Children in employment, male & \\
\hline & & Children in employment, female & \\
\hline & & Children in employment, total & No risk \\
\hline & \multirow[t]{3}{*}{ Forced labour } & Goods produced by forced labour & \\
\hline & & Frequency of forced labour & Very low risk \\
\hline & & Trafficking in persons & \\
\hline & \multirow[t]{3}{*}{ Fair salary } & Living wage, per month & Very low risk \\
\hline & & Minimum wage, per month & Very low risk \\
\hline & & Sector average wage, per month & Very low risk \\
\hline & Working time & Weekly hours of work per employee & Medium risk \\
\hline & \multirow[t]{3}{*}{ Discrimnation } & Women in the sectoral labour force & Medium risk \\
\hline & & Men in the sectoral labour force & Very low risk \\
\hline & & Gender wage gap & Medium risk \\
\hline & \multirow[t]{5}{*}{ Health and safety } & Rate of non-fatal accidents at workplace & Very low risk \\
\hline & & Rate of fatal accidents at workplace & Very low risk \\
\hline & & DALYs due to indoor and outdoor air and water pollution & Low risk \\
\hline & & Presence of sufficient safety measures & Medium risk \\
\hline & & Workers affected by natural disasters & Low risk \\
\hline & \multirow[t]{2}{*}{ Social benefits, legal issues } & Social security expenditures out of the total GDP & Very low risk \\
\hline & & Evidence of violations of laws and employment regulations & Very low risk \\
\hline & \multirow[t]{4}{*}{ Freedom of association } & Trade union density & Low risk \\
\hline & & Right of association & \\
\hline & & Right of collective bargaining & \\
\hline & & Right to strike & No risk \\
\hline \multirow[t]{4}{*}{ Value chain actors } & Fair competition & $\begin{array}{l}\text { Presence of anti-competitive behaviour or violation of anti-trust } \\
\text { and monopoly legislation }\end{array}$ & Low risk \\
\hline & \multirow[t]{2}{*}{ Corruption } & Public sector corruption & Low risk \\
\hline & & Active involvement of the enterprises in corruption and bribery & Low risk \\
\hline & Promoting social responsibility & Social responsibility along the supply chain & \\
\hline \multirow[t]{13}{*}{ Society } & \multirow[t]{8}{*}{ Contribution to economic development } & Contribution of the sector to economic development & Low Opportunity \\
\hline & & Public expenditure on education & \\
\hline & & Adult illiteracy rate $(15+$ years $)$, male & \\
\hline & & Adult illiteracy rate $(15+$ years $)$, female & \\
\hline & & Adult illiteracy rate $(15+$ years $)$, total & \\
\hline & & Youth illiteracy rate, male & \\
\hline & & Youth illiteracy rate, female & \\
\hline & & Youth illiteracy rate, total & \\
\hline & \multirow[t]{5}{*}{ Health and safety } & Health expenditure, total & Medium risk \\
\hline & & Health expenditure, public & Low risk \\
\hline & & Health expenditure, out-of-pocket & Medium risk \\
\hline & & Health expenditure, external resources & Very low risk \\
\hline & & Life expectancy at birth & No risk \\
\hline \multirow[t]{5}{*}{ Local community } & \multirow[t]{5}{*}{ Access to material resources } & Level of industrial water use (related to total withdrawal) & Very low risk \\
\hline & & $\begin{array}{l}\text { Level of industrial water use (related to actual renewable } \\
\text { resources) }\end{array}$ & Very low risk \\
\hline & & Extraction of biomass (related to area) & \\
\hline & & Extraction of biomass (related to population) & \\
\hline & & Extraction of fossil fuels & \\
\hline
\end{tabular}


Table 3 (continued)

\begin{tabular}{|c|c|c|c|}
\hline Stakeholder & Subcategory & Indicator & Risk level \\
\hline & & Extraction of industrial and construction minerals & \\
\hline & & Extraction of ores & \\
\hline & & Certified environmental management systems (CEMs) & Low risk \\
\hline & Respect of indigenous rights & Presence of indigenous population & \\
\hline & & Human rights issues faced by indigenous peoples & \\
\hline & Safe and healthy living conditions & Pollution level of the country & Medium risk \\
\hline & & Drinking water coverage & Very low risk \\
\hline & & Sanitation coverage & No risk \\
\hline & Local employment & Unemployment rate in the country & Medium risk \\
\hline & Migration & International migrant workers in the sector & \\
\hline & & International migrant stock & \\
\hline & & Net migration rate & Low risk \\
\hline Consumers & Transparency & Presence of business practices deceptive or unfair to consumers & Low risk \\
\hline
\end{tabular}

Table 3 shows the stakeholders, subcategories and all indicators in PSILCA (the 36 indicators used to assess the three lines of wastewater in the new plant are highlighted in light blue) as well as the risk level of each indicator.

The assignment of risk levels to the indicators was carried out by consulting various databases (Istat, Ministero del Lavoro e delle Politiche Sociali, Wage indicator org, ILOSTAT, OECD, WHO) and specific literature, referring to Italy or to Europe, to better reflect the specific goal and scope of the study.

For the remaining indicators, the risk levels were entered as "no data" and analysed by the database with a value equal to very low risk.

The impact assessment method used by PSILCA (Social Impacts Weighting Method) assigns characterisation factors to the various impact categories per sector, previously assessed according to risk level. The working hours of each process are used as an activity variable in order to quantify the social risk, i.e. how much each process affects workers. The software uses the characterisation factors of each input (specific to sector and country) and the working hours of every process to determine the social risk (expressed in medium risk hours for each indicator). For example, if in the process the child labour indicator has a very low risk characterisation factor corresponding to 0.01 and the working hours of that process correspond to $1,0.01$ will be multiplied by 1 .

The relative social impacts within the life cycle are calculated by aggregating the various indicators scaled on the price of the inputs, on the basis of the hours worked and on the characterisation factors.

\section{Results and discussion}

The results were first aggregated by subcategories (Figs. 3, 4 and 5) but are also available by indicator as required by the guidelines (UNEP/SETAC 2009) to ensure the transparency of the case study.

Line 1 has the highest risks, which is certainly due to the fact that the amount of WW with TMAH is the highest, 14 times higher than line 2 and even 43 times higher than line 3 (Fig. 5).

The subcategory most generally affected is "Safe and healthy living conditions" (except for line 1, where this subcategory is surpassed by "Corruption"). This is relevant as it is based on data from three indicators concerning the country's pollution level, the accessibility and availability of clean water and the country's health coverage (Fig. 6).

For all three lines, another high-risk subcategory is "Access to material resources". This subcategory, like the previous one, belongs to the Local Community stakeholder, and evaluates its access to material resources or limitation caused by commercial or industrial activities (Fig. 7).

Industries should, in fact, guarantee and develop infrastructures useful for community access to local material resources (i.e. water, land, mineral and biological resources). To describe this subcategory, the level of industrial water use, the extraction of other material resources, the presence of certified environmental management systems and the potential for material resource conflicts are assessed (Figs. 8 and 9). 


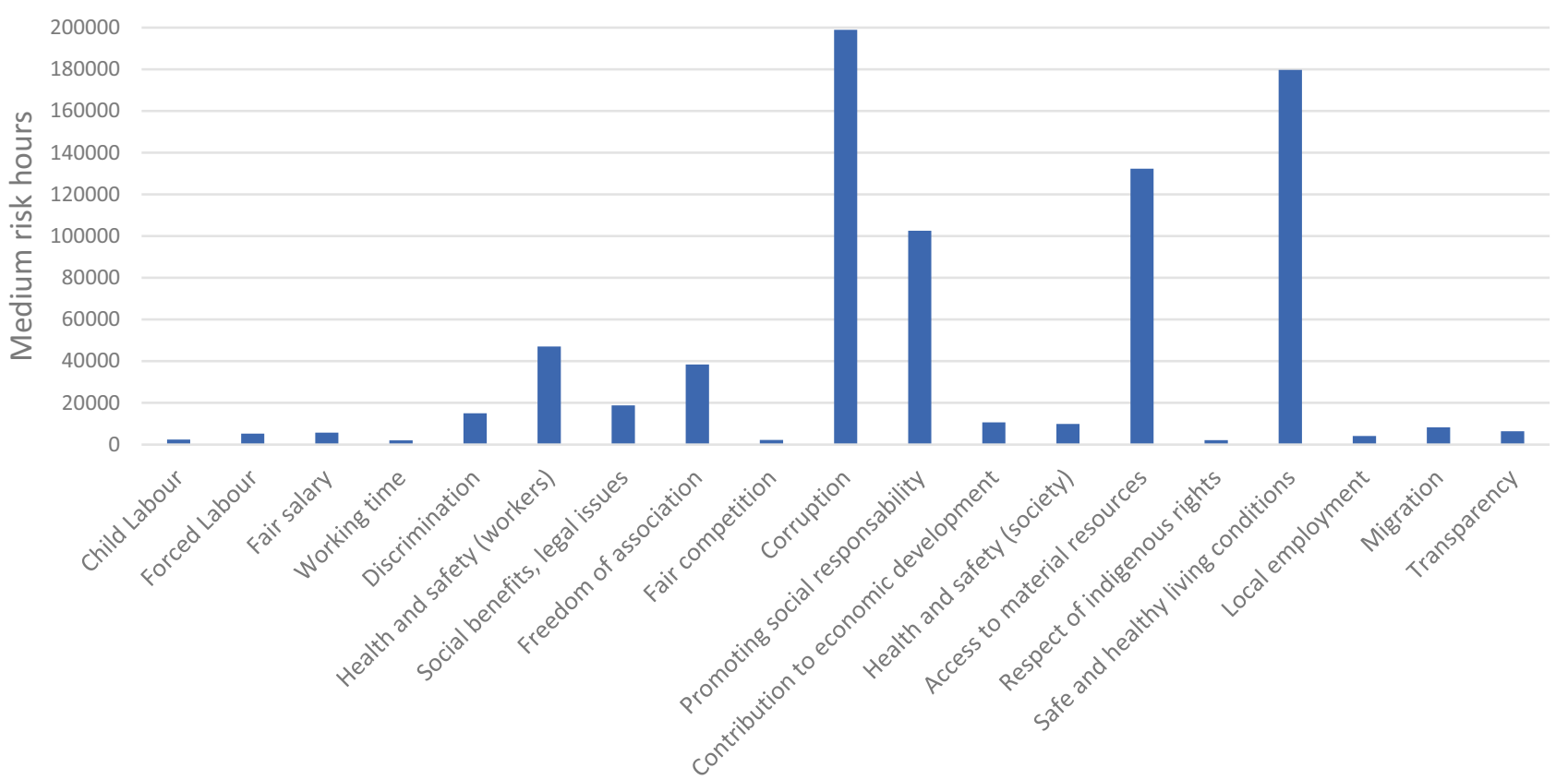

Subcategory

Fig. 3 Results by subcategory for the line $1 \mathrm{TMAH}$

The analysis of results from an indicator perspective (Figs. 10, 11, and 12 in Appendix) for all three lines examined, showing the highest impact is "Public sector corruption", whose indicator is expressed by the Corruption Perception Index (Transparency International 2012). Corruption typically affects public institutions or governments and can have major effects on everyday life. In this case study, corruption is linked to the electrical and chemical sectors, despite the fact that the risk assessment assigned to the company analysed is "low risk" (Table 3 ).

The other impact categories affected are (Eisfeldt and Ciroth 2017):

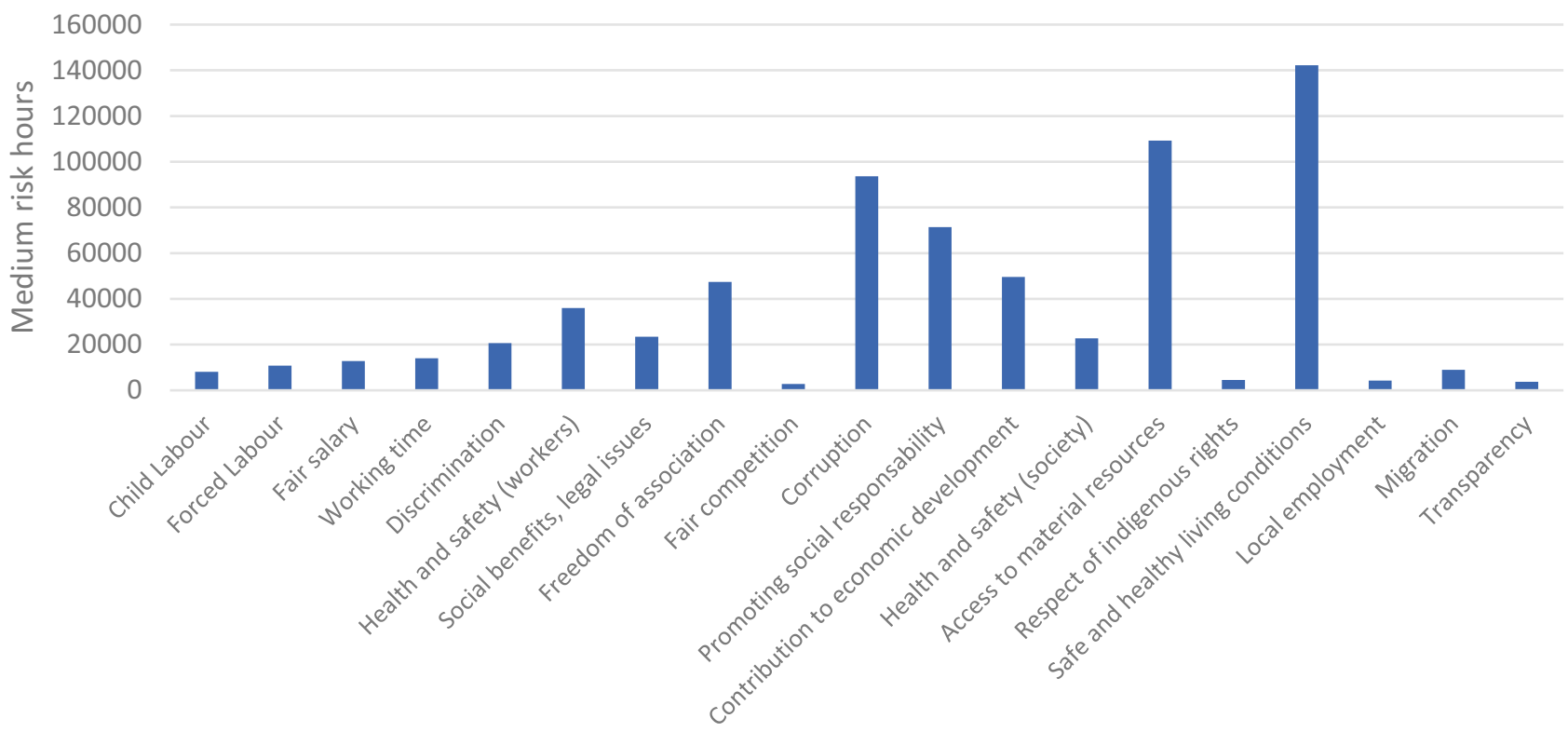

Subcategory

Fig. 4 Results by subcategory for the line $2 \mathrm{BOE}$ 


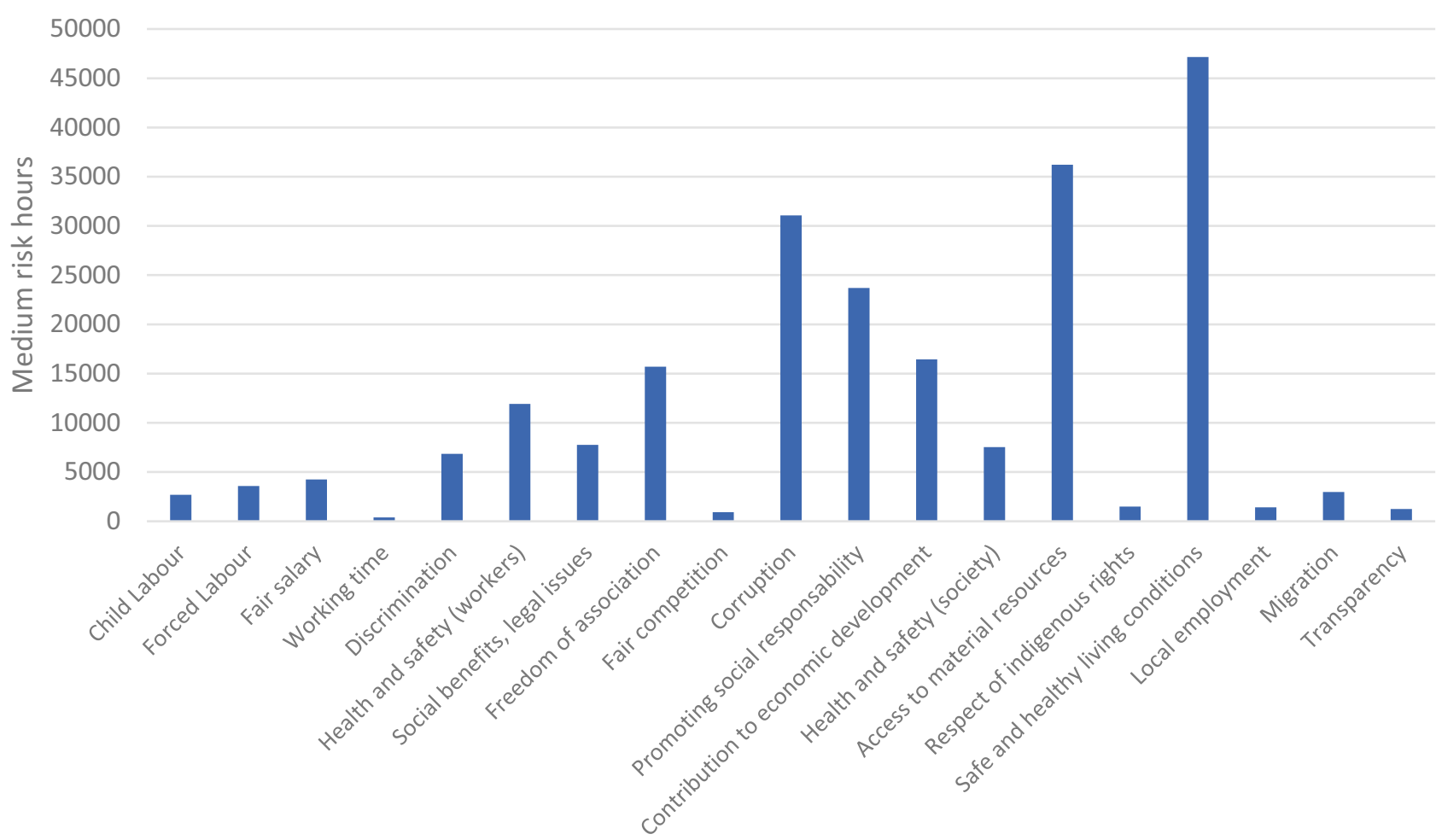

Subcategory

Fig. 5 Results by subcategory for the line 3 SEZ

- "Social responsibility along the supply chain"; the pertinent indicator considers how much companies in specific sectors take into consideration and ensure social responsibility.
- "Contribution to environmental load"; taking into account various airborne emissions (Table 3), this indicator expresses the contribution of a given sector to global warming, environmental pollution and, ultimately, health

\section{Contribution of social indicators for Society}

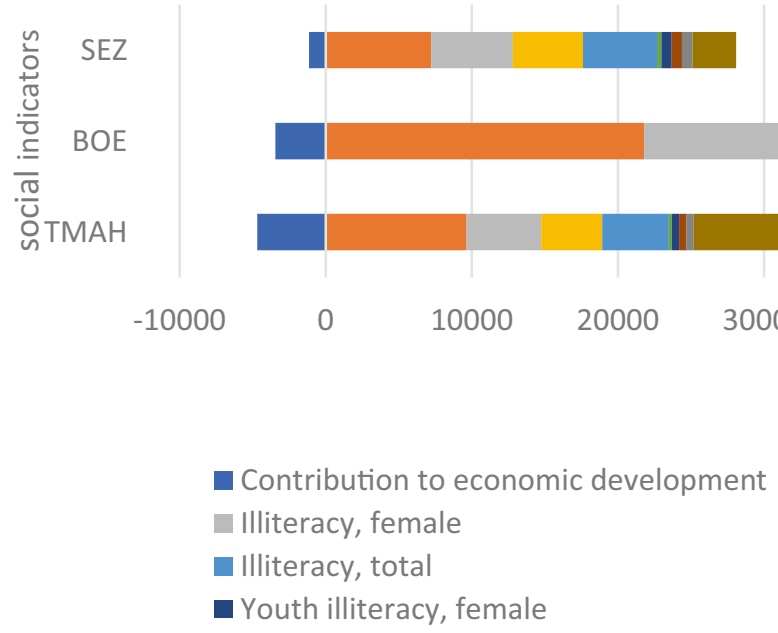

Fig. 6 Relative contribution to social indicators in the stakeholders society, considered for line 1 TMAH, line 2 BOE and line 3 SEZ processes (functional unit: annual generation of wastewater, $6300 \mathrm{t}$ TMAH, $435 \mathrm{t}$ BOE, $145 \mathrm{t}$ SEZ) 
Fig. 7 Relative contribution to social indicators in the stakeholders Value Chain Actors, considered for line $1 \mathrm{TMAH}$ line 2 BOE and line 3 SEZ processes (functional unit: annual generation of wastewater, $6300 \mathrm{t}$ TMAH, 435 t BOE, 145 t SEZ)
Contribution of social indicators for Value Chain Actors

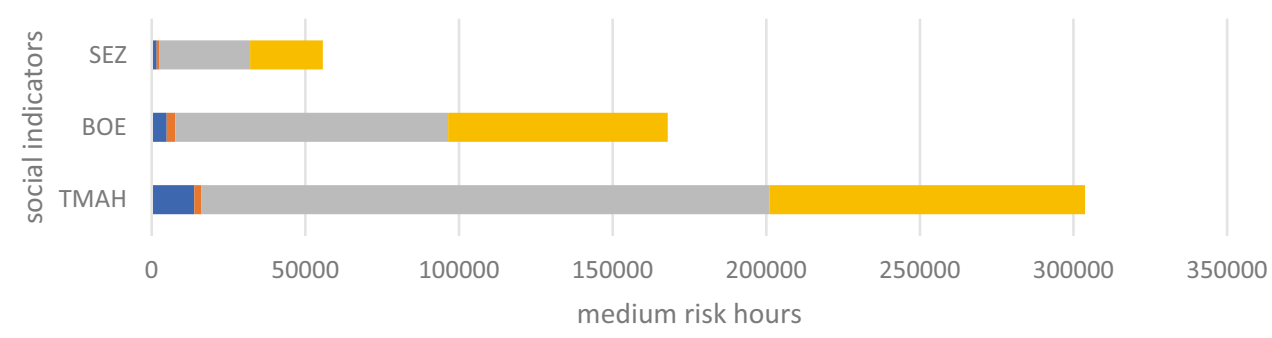

- Active involvement of enterprises in corruption and bribery

Anti-competitive behaviour or violation of anti-trust and monopoly legislation

Public sector corruption

Social responsibility along the supply chain risks. In this case study, reference is made to the supply chain of the sectors concerned.

- "Certified environmental management systems"; for a given sector this indicator takes into consideration the ratio between the number of certified Environmental Management Systems (EMS) and the number of employees in that sector.

- "Industrial water depletion"; this indicator assesses the degree of industrial water consumption by relating the amount of water withdrawn for industrial purposes to the overall water withdrawal for other uses (agricultural, industrial and municipal) as well as to the total renewable water resources.

- "Sanitation coverage"; this indicator assesses a population's access to improved sanitation facilities, and thus the associated exposure to infectious disease risks, assuming that poor access to such facilities is associated with lower levels of wastewater treatment. The indicator also offers information on overall water quality.
- "Trade union density"; this indicator expresses the spread and freedom of trade union culture in a given sector; thus, in the final analysis, the right of workers to organize freely in trade unions in that sector.

The positive impact of the indicator "Contribution of the sector to economic development" is very significant. This indicator evaluates the contribution of a given sector to the economic development of a whole country and is determined as that sector's contribution to the country's Gross Domestic Product GDP, and it is the only positive indicator considered (Eisfeldt and Ciroth 2017). This indicator represents all types of sector contributions to economic development, e.g. investment in business/infrastructure, job creation, specific education and training. For this reason, it is expressed in levels of opportunity: low levels of opportunity assume that the sector, compared to others, does not make significant contributions to economic development, while high levels represent a positive impact. This result stems from the
Fig. 8 Relative contribution to social indicators in the stakeholders Local Community considered for line 1 TMAH, line 2 BOE and line 3 SEZ processes (functional unit: annual generation of wastewater, $6300 \mathrm{t}$ TMAH, 435 t BOE, 145 t SEZ)

\section{Contribution of social indicators for Local Community}

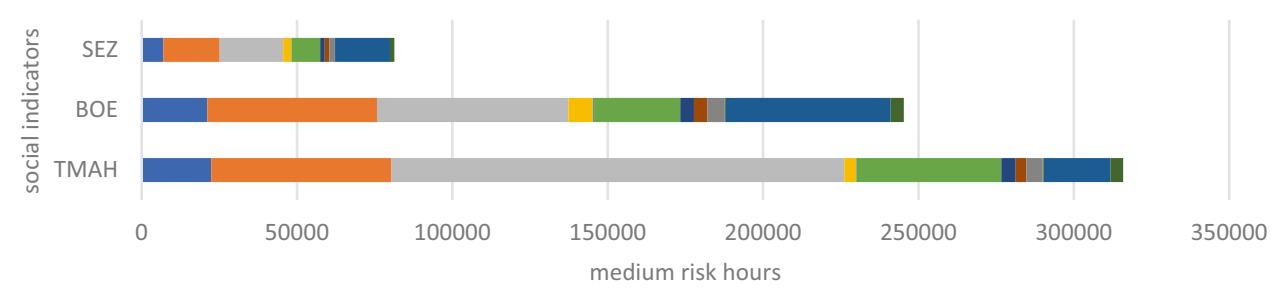

- Certified environmental management system

Drinking water coverage

- Industrial water depletion

- International migrant workers (in the sector/ site)

- Net migration

- Unemployment 


\section{Contribution of social indicators for Workers}

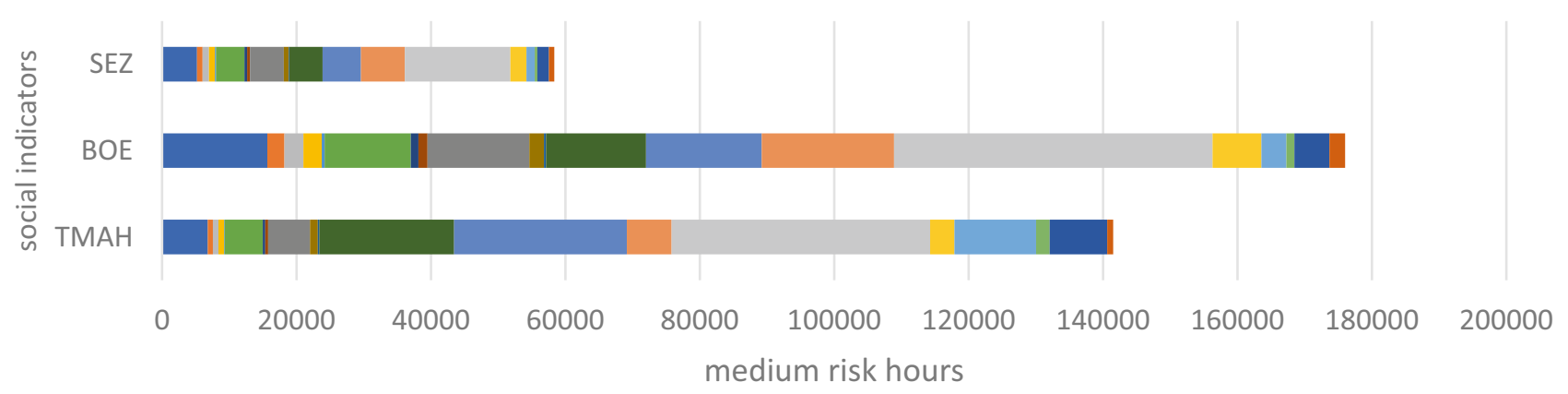

$\begin{array}{ll}\text { - Association and bargaining rights } & \text { Child Labour, female } \\ \square \text { Child Labour, male } & \text { Child Labour, total } \\ \square \text { DALYs due to indoor and outdoor air and water pollution } & \square \text { Fair Salary } \\ \square \text { Fatal accidents } & \square \text { Frequency of forced labour } \\ \square \text { Gender wage gap } & \square \text { Goods produced by forced labour } \\ \square \text { Men in the sectoral labour force } & \square \text { Non-fatal accidents } \\ \square \text { Safety measures } & \square \text { Social security expenditures } \\ \square \text { Trade unionism } & \square \text { Trafficking in persons } \\ \square \text { Violations of employment laws and regulations } & \square \text { Weekly hours of work per employee } \\ \square \text { Women in the sectoral labour force } & \square \text { Workers affected by natural disasters }\end{array}$

Fig. 9 Relative contribution to social indicators in the stakeholder workers considered for line 1 TMAH, line 2 BOE and line 3 SEZ processes (functional unit: annual generation of wastewater, $6300 \mathrm{t}$ TMAH, $435 \mathrm{t}$ BOE, $145 \mathrm{t} \mathrm{SEZ)}$

contribution of the sectors from which our inputs come, in this case from the "Chemicals, chemical products and manmade fibres" sector, which in Italy is growing both in terms of imports and exports.

PSILCA analysis for stakeholders shows the Local Community to be the most affected group (Fig. 6).

The impacts on "Local Communities" are mainly generated by: "Contribution to environmental load", "Certified environmental management system" and the "Use of industrial water". These indicators have negative impacts on the environment, even though they are here considered for their associated health risks.

Value chain actors (Fig. 7) such as Local Community (Fig. 6) show results exceeding 300,000 mrh for line 1. In this case, the indicators that most contribute to the result are "Corruption" and "Social responsibility along the supply chain".
Social consequences for employees (Fig. 8) across all three lines include a high vulnerability related to "Gender inequality", "Safety measures" and "Amount of working hours".

Line 2 BOE indicators contribute most to the impacts on stakeholders Society (Fig. 9) and Workers.

The Sankey diagram shows (Fig. 13 in Appendix) that the direct contribution from the TMAH line to the impact category "contribution to environmental load" is very low (0.041\%), compared to the indirect $(97.37 \%$ upstream sectors) one. Indeed, the risk is spread throughout the supply chain, according to the results of our analysis from the 3 WWT lines with innovative technology; this implies that the overall risk is mainly related to sectors upstream the TMAH, BOE and SEZ processes. 


\section{Line 1 TMAH results}

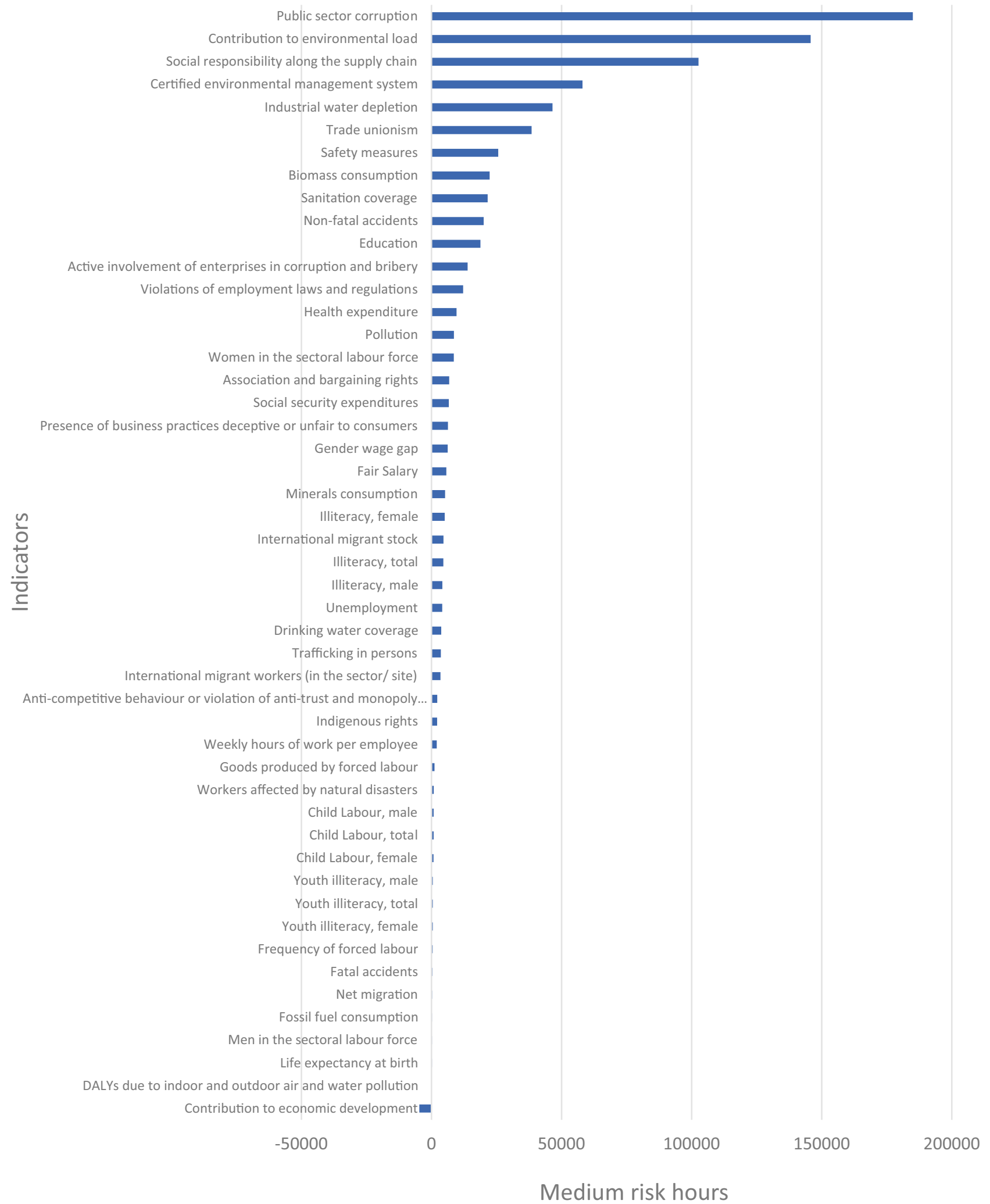

Fig. 10 Results by social indicators of the TMAH lines of the plant, in mrh for the FU (functional unit: annual production of wastewater $6300 \mathrm{t}$ TMAH) 


\section{Line 2 BOE results}

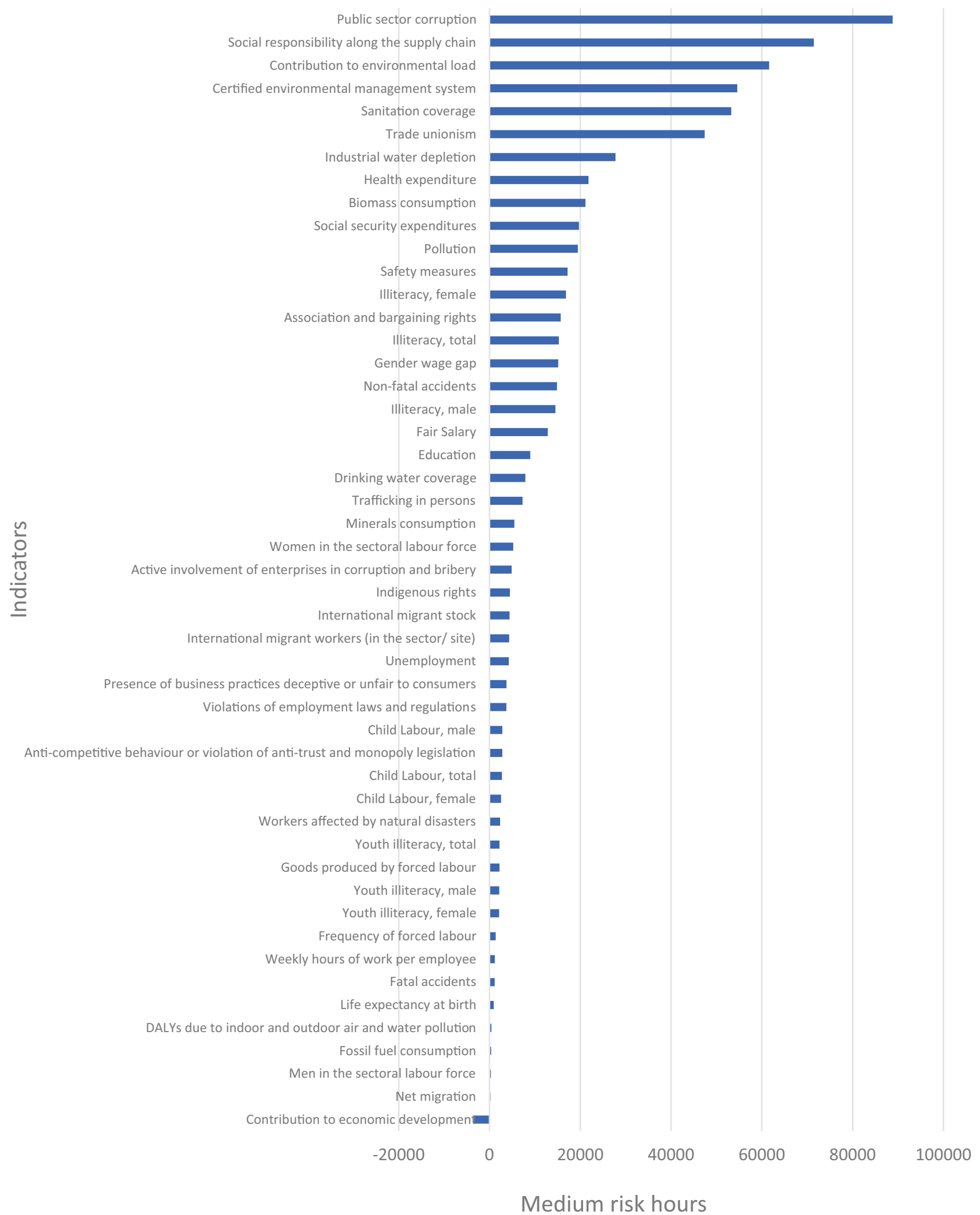

Fig. 11 Results by social indicators of the BOE lines of the plant, in $\mathrm{mrh}$ for the FU (functional unit: annual production of wastewater, $435 \mathrm{t} \mathrm{BOE}$ ) 


\section{Line 3 SEZ results}

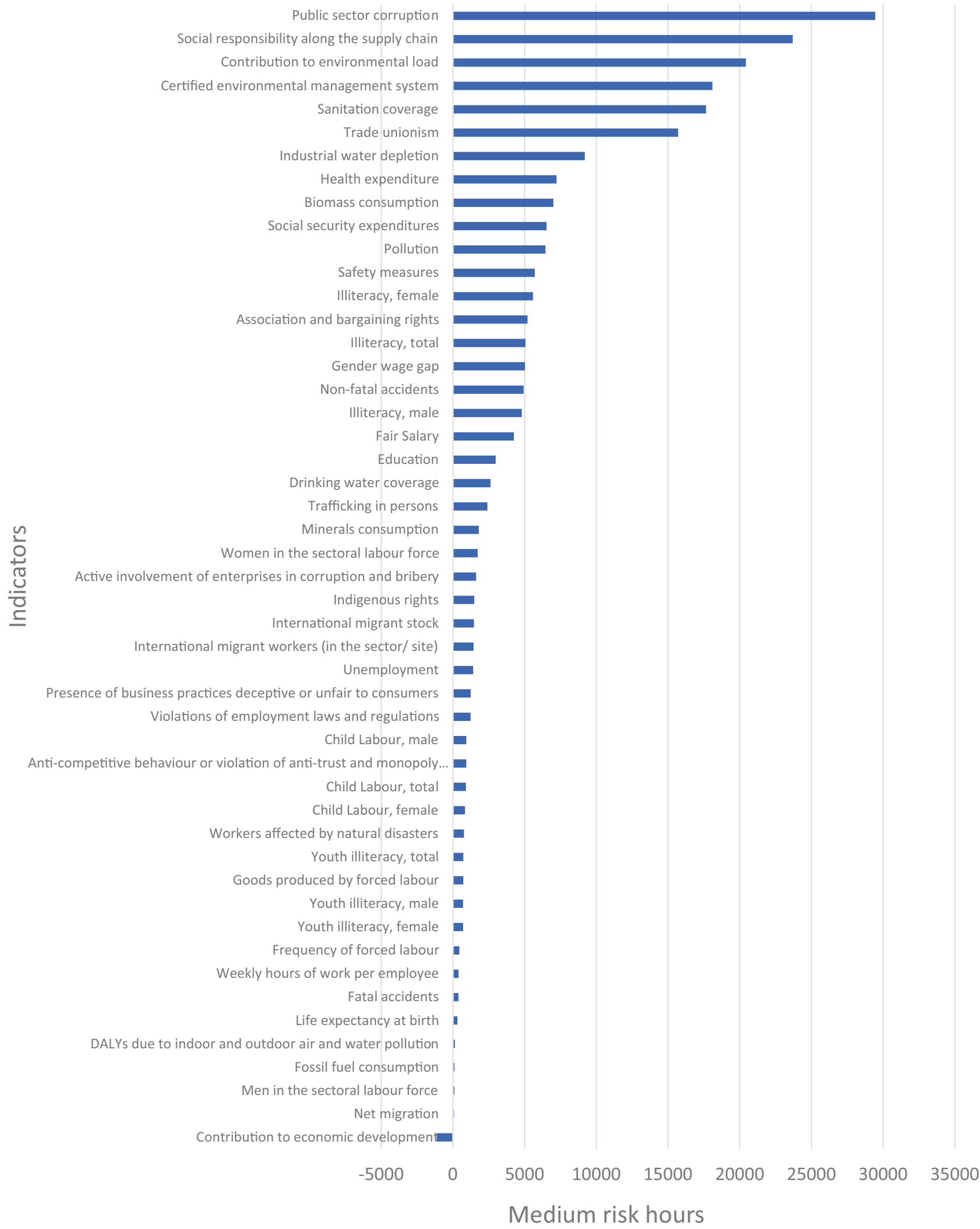

Fig. 12 Results by social indicators of the SEZ lines of the plant, in mrh for the FU (functional unit: annual production of wastewater $145 \mathrm{t}$ SEZ) 


\section{Conclusions}

This paper presented an S-LCA of a new plant for the wastewater treatment of an E\&S manufacturing company in Italy, using the PSILCA database.

The specific objective of the semi-industrial plant developed was to enable the treatment of spent TMAH, ammonium fluoride solution, nitrates, fluorides, phosphoric acid and acetic acid. This new pilot plant contributed to identify priority hazardous substances, such as TMAH, considering the precautionary principle, relying on the determination of any potentially adverse effects of the product and on a scientific assessment of the risk. Furthermore, the full-scale plant will be able to process the concentrated TMAH wastewater which is currently disposed of as waste. The positive results of this project would make it possible first of all to obtain a decrease in the concentration of TMAH at the discharge of industrial waters, thus substantially reducing the economic, environmental and social impact of the disposal of this substance.

In some sectors, such as the electronics and semiconductor one, it is necessary to start evaluating, also from a social point of view, civil and industrial plants that may have important environmental impacts. Bearing in mind that there is, in general, a lack of studies considering environmental and social impacts in an integrated way, and that S-LCA has not been widely used in the WWT field, as demonstrated by the literature analysis, this work is the first that uses PSILCA database to evaluate an industrial wastewater plant.

A consideration regarding the PSILCA database concerns the difficulty in explaining the unit of measurement of the results (mrh), particularly for those subcategories not linked to working conditions, e.g. access to material resources. Furthermore, the type of results that the databases return seems to be meaningful when a comparison with a similar product is allowed, as there is no absolute reference scale capable of defining the intensity of a given impact. In this case, it will be possible to assess which of the two products carries more social risk. The lack of reference scales to assess social risks is due to the reason that the social aspects are context-related and linked to cultural values.

The difficulty in presenting, commenting and understanding the results is an issue that the S-LCA will have to improve, especially for companies that want to use the results to develop policies or to communicate them to a wider audience.

Furthermore, PSILCA only assesses social risks, i.e. indicators which, if they have a significant result (expressed in mrh), are social issues, but it does not allow a precise evaluation of the possible positive effects of the company's performance. Moreover, Impact Assessment used in the database gives the same weight to all indicators and sub-categories, which leads to flattening the analysis. Recently, the weighing of indicators has become a fundamental step in S-LCA in order to give each indicator its relative importance (or contribution) to the performance of a specific impact subcategory.
Finally, it is worthy to underline the difficulty in modelling a waste in a database that currently works for the evaluation of products. Indeed, the results are expressed in terms of overall risk, measured as mrh per unit of output value, which makes little sense when it comes to waste, because this is usually a cost for companies and has no economic value.

Concerning the main limitation of the study, the comparison between the current management and the new plant would certainly have allowed us to appreciate the difference between the social impacts. To do this, external companies had to be included in the system boundaries.

The most meaningful social impacts concern aspects related to the supply chain. However, it is necessary to highlight the presence of a positive impact related to sectors that contribute to the economic development of the country.

S-LCA takes into account all stages upstream of the supply chain. Social risks being mostly found in sectors that are suppliers of the WWT innovative technology considered demonstrates the high analytical capacity of life cycle analysis, highlighting which countries, sectors and locations contribute most to the risk. The high incidence of indirect impacts substantiates the meaning of adopting a life-cycle approach in the assessment and management of social risks within global supply chains.

As a concluding remark, it can be observed that social aspects are often the most neglected in sustainability assessments, while a growing demand for company behaviour is spreading. This work provides a relevant contribution to the development of social assessments from a practical point of view, as it is an implementation of the S-LCA in an operational reality of an innovative industrial context.

Funding Open access funding provided by Università degli Studi G. D'Annunzio Chieti Pescara within the CRUI-CARE Agreement. This study was carried out in the framework of the Life Bitmaps project funded by the European Union Grant Agreement No. LIFE 15 ENV/ IT 000332 .

Data availability Data supporting the results of this study will be made available upon reasonable request and within the limits of the informed consent provided by the corresponding author (LP) and the company promoting the study.

Open Access This article is licensed under a Creative Commons Attribution 4.0 International License, which permits use, sharing, adaptation, distribution and reproduction in any medium or format, as long as you give appropriate credit to the original author(s) and the source, provide a link to the Creative Commons licence, and indicate if changes were made. The images or other third party material in this article are included in the article's Creative Commons licence, unless indicated otherwise in a credit line to the material. If material is not included in the article's Creative Commons licence and your intended use is not permitted by statutory regulation or exceeds the permitted use, you will need to obtain permission directly from the copyright holder. To view a copy of this licence, visit http://creativecommons.org/licenses/by/4.0/.

\section{Appendix}




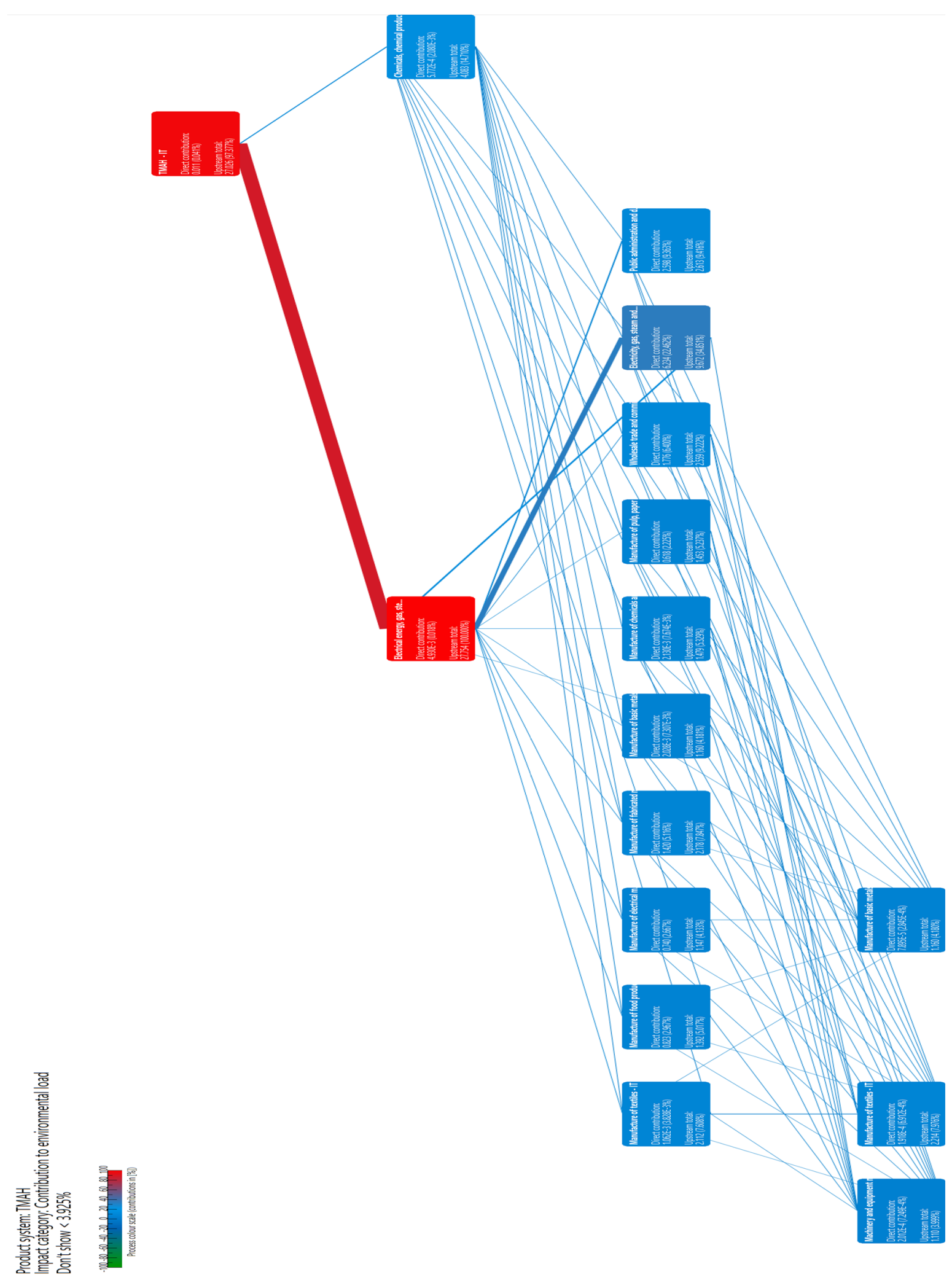

Fig. 13 Sankey diagram for the TMAH line, overall structure and zoom. The figure shows the contribution of the different Country Specific Sector to the overall risk in the social impact category "contribution to environmental load" 


\section{References}

Amaral KGC, Aisse MM, Possetti GRC (2019) Sustainability assessment of sludge and biogas management in wastewater treatment plants using the LCA technique. Rev Ambient Água 14(5):e2371. ISSN 1980-993X

Bui XT, Vo TPT, Ngo HH, Guo WS, Nguyen TT (2016) Multicriteria assessment of advanced treatment technologies for micropollutants removal at large-scale applications. Sci Total Environ 563-564:1050-1067

Byrne DM, Lohman HA, Cook SM, Peters GM, Guest JS (2017) Life cycle assessment (LCA) of urban water infrastructure: emerging approaches to balance objectives and inform comprehensive decision-making. Environ Sci: Water Res Technol 3(6):1002-1014

De Michelis I, Innocenzi V, Corradini V, Zueva S, Ippolito NM, Centofanti M, Tizzani C, Affatato M (2019) Pilot technology for aerobic biodegradation of spent TMAH Photoresist solution in Semiconductor industries, http://www.lifebitmaps.eu/pdf/annex b4_1_report_on_pilot_plant_validation_test.pdf. Accessed 10 Oct 2020

Eisfeldt F, Ciroth A (2017) PSILCA-A product social impact life cycle assessment database. Database version 2. Berlin: GreenDelta GmbH

Eora (2015) http://worldmrio.com/. Accessed 07/2020

European Commision EC (2006) Regulation (EC) no 1907/2006 of the European Parliament and of the Council of 18 December 2006 concerning the Registration, Evaluation, Authorisation and Restriction of Chemicals (REACH), establishing a European Chemicals Agency, amending Directive 1999/45/EC and repealing Council Regulation (EEC) No 793/93 and Commission Regulation (EC) No 1488/94 as well as Council Directive 76/769/EEC and Commission Directives 91/155/EEC, 93/67/EEC, 93/105/EC and 2000/21/EC, 2006, https://eur-lex.europa.eu/legal-content/ EN/TXT/HTML/?uri=CELEX:02006R1907-20090627\&from= IT. Accessed 14 Oct 2020

European Commission EC, 7th Environment Action Programme (2013) https://ec.europa.eu/environment/action-programme/. Accessed 15 Oct 2020

European Commission EC, EU Water Framework Directive 2000/60/ EC (2020) https://eur-lex.europa.eu/legal-content/EN/TXT/?uri= CELEX:32000L0060. Accessed 9 Oct 2020

European Environmental Agency - EEA (2019) Chemicals in Europe: understanding impacts on human health and the environment. https://www.eea.europa.eu/articles/chemicals-in-europeunderstanding-impacts. Accessed 15 Oct 2020

Franze J, Ciroth A (2011) A comparison of cut roses from Ecuador and the Netherlands. Int J Life Cycle Assess 16:366-379

García-Sánchez M, Güereca LP (2019) Environmental and social life cycle assessment of urban water systems: the case of Mexico City. Sci Total Environ 693:133464

Gómez-López MD, Bayo J, García-Cascales MS, Angosto JM (2009) Decision support in disinfection technologies for treated wastewater reuse. J Clean Prod 17(16):1504-1511

Kamali M, Persson KM, Costa ME, Capela I (2019) Sustainability criteria for assessing nanotechnology applicability in industrial wastewater treatment: current status and future outlook. Environ Int 125:261-276

Kobayashi Y, Peters GM, Ashbolt NJ, Heimersson S, Svanström M, Khan SJ (2015) Assessing burden of disease as disability adjusted life year in life cycle assessment. Water Res 79:26-38.

Innocenzi V, Zueva S, Prisciandaro M, De Michelis I, Di Renzo A, Di Celso GM, Vegliò F (2019) Treatment of TMAH solutions from the microelectronics industry: a combined process scheme. J Water Process Eng 31:100780
Istat (2014) Annuario statistico italiano -2014, Ambiente ed energia. https://www.istat.it/it/files/2014/11/C02.pdf. Accessed 04/21

Istituto Superiore di Sanità ISS (2013) Circular note of Istituto Superiore di Sanità, 30/1/2013 protocol n. 3076

Lee CY, Wang LM, Ngo MH, Chen TH, Cheng HH (2016) Acute toxicity assessment of TFT-LCD wastewater using Daphnia similis and Cyprinus carpio. Process Saf Environ Protect 104:499-506

Life Bitmaps (2020) Pilot technology for aerobic biodegradation of spent TMAH photoresist solution in semiconductor industriesLayman's Report. http://www.lifebitmaps.eu/pdf/lifebitmapsreport-stampa.pdf. Accessed 15 Oct 2020

Lin CC, Yang CC, Ger J, Deng JF, Hung DZ (2010) TMAH poisoning. Clin Toxicol 48:213-217

Molinos-Senante M, Gómez T, Caballero R, Hernández-Sancho F, Sala-Garrido R (2015) Assessment of wastewater treatment alternatives for small communities: an analytic network process approach. Sci Total Environ 532:676-687

Molinos-Senante M, Gómez T, Garrido-Baserba M, Caballero R, SalaGarrido R (2014) Assessing the sustainability of small wastewater treatment systems: a composite indicator approach. Sci Total Environ 607-617

Mori IC, Arias-Barreiro CR, Koutsaftis A, Ogo A, Kawano T, Yoshizuka K, Inayat-Hussain SH, Aoyama I (2015) Toxicity of tetramethylammonium hydroxide to aquatic organisms and its synergistic action with potassium iodide. Chemosphere 120:299-304

OECD (2012) SIDS Initial Assessment profiles agreed in the course of the OECD HPV chemicals programme from 1993 to 2011- Series on testing and assessment No. 166

Opher T, Shapira A, Friedler E (2018) A comparative social life cycle assessment of urban domestic water reuse alternatives. Int J Life Cycle Assess 23(6):1315-1330

Padilla-Rivera A, Morgan-Sagastume JM, Güereca-Hernández LP (2019) Sustainability assessment of wastewater systems: an environmental and economic approach. J Environ Prot 10:241-259

Padilla-Rivera A, Morgan-Sagastume JM, Noyola A, Güereca LP (2016) Addressing social aspects associated with wastewater treatment facilities. Environ Impact Assess Rev 57:101-113

Ramirez PKS, Petti L, Haberland NT, Ugaya CML (2014) Subcategory assessment method for social life cycle assessment. Part 1: methodological framework. Int J Life Cycle Assess, v. 19, p. 1515-1523. https://doi.org/10.1007/s11367-014-0761-y

Ren J, Liang H (2017) Multi-criteria group decision-making based sustainability measurement of wastewater treatment processes. Environmental Assessment Review 65:p91-99

Regional Agency for the Environment Protection of Abruzzo Region. 2013. Technical evaluation note elaborated by the Regional Agency for the Environment Protection of Abruzzo region, 30/09/2013 protocol n. 10307

Sadhukhan J, Gadkari S, Martinez-Hernandez E, Ng KS, Shemfe B, Torres Garcia E, Lynch J (2019) Novel macroalgae (seaweed) biorefinery systems for integrated chemical, protein, salt, nutrient and mineral extractions and environmental protection by green synthesis and life cycle sustainability assessments. Green Chem 21:2635

Sharma AK, Grant AL, Grant T, Pamminger F, Opray L (2009) Environmental and Economic Assessment of Urban Water Services for a Greenfield Development. Environ Eng Sci 26:921-934.

Shemfe MB, Gadkari S, Sadhukhan M (2018) Social hotspot analysis and trade policy implications of the use of bioelectrochemical systems for resource recovery from wastewater. Sustainability 10(9):3193

Transparency International (2012) https://www.transparency.org/en/ cpi/2012/index/nzl\# . Accessed 20 Oct 2020

Traverso M, Finkbeiner M, Jorgensen A, Schneider L (2012) Life cycle sustainability dashboard. J Ind Ecol 16(5):680-688 
UN Water (2020) https://www.unwater.org/water-facts/quality-andwastewater/. Accessed 2 Mar 2020

UNEP/SETAC (2009) Guidelines for social life cycle assessment of products. United Nations Environment Programme, Paris. http:// www.unep.org/pdf/DTIE_PDFS/DTIx 1 164xPA-guidelines_ sLCA.pdf. Accessed 10 Feb 2020

Vegliò F (2016) Pilot technology for aerobic biodegradation of spent TMAH-photoresist solution in semiconductor industries. https:// www.lifebitmaps.eu/pdf/workshop-laquila-2017/Presentazione_ Vegliò.pdf
Zortea B, Maciel VG, Passuello A (2017) Sustainability assessment of soybean production in Southern Brazil: A life cycle approach. Sustain Prod Consum 14(1):12-112. https://doi.org/10.1016/j.spc. 2017.11.002

Publisher's Note Springer Nature remains neutral with regard to jurisdictional claims in published maps and institutional affiliations.

\section{Authors and Affiliations}

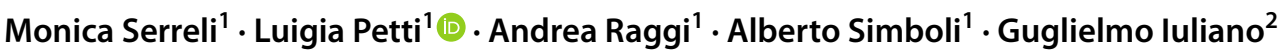

1 Department of Economic Studies, "G. D’Annunzio" University, Viale Pindaro, 42, 65127 Pescara, Italy
2 LFoundry S.R.L, Via Pacinotti 7, 67051 Avezzano, L’Aquila, Italy 